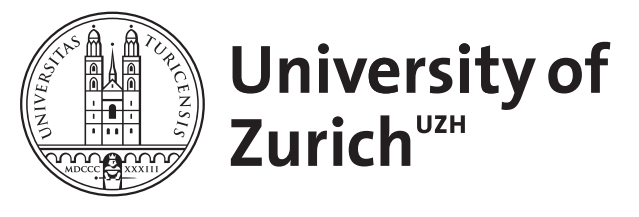

\title{
Humor and strengths of character
}

\author{
Müller, L ; Ruch, Willibald
}

\begin{abstract}
Humor in the Values in Action (VIA) Classification of Strengths is conceptualized as a unipolar and unidimensional strength and is subsumed under the virtue of transcendence. Its scope is intentionally restricted to forms of humor that serve some moral good. The present study (N 1/4 203) investigated the relation between five dimensions of humorous conduct, sense of humor, and the VIA-Inventory of Strengths (VIA-IS). Results show (1) that the VIA-humor correlated with socially warm and competent humor, and the sense of humor, all with a common basis in humanity. (2) Each humor style showed relations to strengths. Additionally, strengths related to the virtue of temperance were also related to not showing mean-spirited and earthy forms of humor. Hence, humor in the VIA-IS can be well-located in established humor taxonomies, but does not cover all of the virtue-related humorous behaviors. Further research is requested to investigate the role of virtue in humor.
\end{abstract}

DOI: https://doi.org/10.1080/17439760.2011.592508

Posted at the Zurich Open Repository and Archive, University of Zurich

ZORA URL: https://doi.org/10.5167/uzh-49688

Journal Article

Accepted Version

Originally published at:

Müller, L; Ruch, Willibald (2011). Humor and strengths of character. Journal of Positive Psychology, 6(5):368-376.

DOI: https://doi.org/10.1080/17439760.2011.592508 
This manuscript was published as:

Müller, L., \& Ruch, W. (2011). Humor and strengths of character. The Journal of Positive Psychology, 6, 368-376. 


\title{
HUMOR AND STRENGTHS OF CHARACTER
}

\author{
Liliane Müller ${ }^{\mathrm{a}, \mathrm{b}}$ and Willibald Ruch ${ }^{\mathrm{a}, \mathrm{b}^{*}}$ \\ ${ }^{a}$ Department of Psychology, University of Zurich, Zurich, Switzerland; ${ }^{b}$ Department \\ of Psychology, Swiss University of Distance Education, Brig, Switzerland
}

Running head: HUMOR AND THE GOOD CHARACTER

\section{*Corresponding author:}

Willibald Ruch, Section on Personality and Assessment, Department of Psychology, University of Zurich, Binzmuehlestrasse 14/7, 8050 Zurich, Switzerland.

Phone: office: +41 4463575 20; Fax: +41 446357529 89; e-mail:

w.ruch@psychologie.uzh.ch

Manuscript information: abstract 146 words, main text 5689 words, 16 references, 2 tables 


\section{Abstract}

Humor in the VIA-Classification of Strengths is conceptualized as a unipolar and unidimensional strength and is subsumed under the virtue of transcendence. Its scope is intentionally restricted to forms of humor that serve some moral good. The present study $(N=203)$ investigated the relation between five dimensions of humorous conduct, sense of humor, and the VIA-IS. Results show (1) that the VIA-humor correlated with socially warm and competent humor, and the sense of humor, all with a common basis in humanity. (2) Each humor style showed relations to strengths. Additionally, strengths related to the virtue of temperance were also related to not showing mean-spirited and earthy forms of humor. Hence, humor in the VIA-IS can be well located in established humor taxonomies, but does not cover all of the virtue related humorous behaviors. Further research is requested to investigate the role of virtue in humor.

Keywords: Humor, character strength, virtue, sense of humor 


\section{Humor and strengths of character}

\section{Introduction}

Under the umbrella term of Positive Psychology, the VIA-Classification of Strengths (Peterson \& Seligman, 2004) was developed for providing a "manual of the sanities", i.e., traits that contribute to and enable a good life. Twenty-four character strengths were assigned to six virtues (wisdom and knowledge, courage, humanity, justice, temperance, and transcendence) recurring in literature and over time. The Values in Action Inventory of Strengths (VIA-IS, Peterson, Park \& Seligman, 2005) is current standard for the assessment of these character strengths among adults.

Humor is one of the 24 character strengths in the VIA-classification and it is understood as a morally valued trait, as potentially virtuous. Humor contributes to positive psychological functioning. Peterson and Seligman (2004) did define the humorous individual as one "... who is skilled at laughing and teasing, at bringing smiles to the faces of others, at seeing the light side, and at making (not necessarily telling) jokes" (p. 530). Humor is among the most highest endorsed strengths (Park, Peterson \& Seligman, 2006), among those strengths yielding the highest correlations with subjective well-being and life satisfaction (see Park, Peterson \& Seligman, 2004; Peterson, Ruch, Beermann, Park \& Seligman, 2007; Ruch, Proyer, Esser \& Mitrache, 2011; Ruch, Proyer, Harzer, Park, Peterson, \& Seligman, 2010), and it was found to mediate effects on higher satisfaction with life in people with physical illness (Peterson, Park, \& Seligman, 2006).

Humor as a character strengths and earlier concepts of humor Peterson and Seligman (2004) were not the first ones to operationalize humor. In the past humor was seen as a temperament, worldview, aesthetic perception, ability, and 
attitude, and numerous tests were designed for its measurement (see Ruch, 2008). It is of interest to have a closer look at the conceptual overlap between humor as a strength and the other approaches.

Peterson and Seligman (2004) acknowledge that there are many facets of humor. "The domain of humor is vast and varied, and there exists a huge terminology for describing its types. Some forms are clearly mean (e.g., mockery, ridicule, sarcasm), and others on the border (e.g., parody, practical jokes). We exercise our prerogative by focusing on those forms of humor that serve some moral good-by making the human condition more bearable by drawing attention to its contradictions, by sustaining good cheer in the face of despair, by building social bonds, and by lubricating social interaction" (p. 530). Thus, from a universe of humor behaviors they selected the ones potentially virtuous. This allows deriving hypotheses what aspects of humor will relate to humor as a strength and which ones will not.

In the present article two approaches are selected to serve as a reference. First, the conceptualization by McGhee (1999) is chosen as a theory driven approach to the sense of humor. McGhee (1999) defines humor as a form of play, the play with ideas. A playful mind is important to successfully process humorous stimuli. Without this playful mind, the same event is perceived, for example, as frightening, puzzling or annoying, but not as funny. Based on this McGhee introduced a multi-faceted concept of sense of humor in which playfulness (as a frame of mind) forms the basis for the sense of humor, which is composed of six less basic components (facets) or humor skills. These are supposed to be hierarchically organized from enjoyment of humor to finding humor under stress, as the ones higher in the hierarchy should be more difficult to develop. To measure these facets, McGhee (1999) introduced the rationally constructed sense of humor scale $(S H S)$. 
We hypothesize that humor as a character strength will strongly overlap with the sense of humor (i.e., the sum of the six facets) without being identical to it. Some facets, like humor under stress or finding humor in everyday life will more strongly overlap while facets like enjoyment of humor (which does not reflect moral goodness or excellence) will only marginally overlap.

The second approach selected as a reference (Craik, Lampert, \& Nelson, 1996) covers the most heterogeneous and comprehensive set of humor behaviors--and consequently with five orthogonal factors also the most differentiated structural model of humor so far (Ruch et al., 2011). Craik et al. (1996) collected specific forms of everyday humorous conduct from an act frequency perspective and from a survey of the theoretical and empirical psychological research literature on humor, and they arrived at a set of 100 non-redundant statements, which form the Humorous Behavior Q-Sort Deck (HBQD). In a search for coherent themes a principal component analysis yielded bipolar factors of socially warm versus cold, competent versus inept, earthy versus repressed, reflective versus boorish, and benign versus mean-spirited humor. The highest intercorrelation $(r=.30)$ among the factors was found between the socially warm vs. cold and competent vs. inept styles. There is empirical evidence that the sense of humor relates most strongly to the socially warm humor style and to a minor extent to the competent humor style; this could be found for both an index composed of HBQD items (Craik et al., 1996) as well as the SHS (Ruch et al., 2011).

We expect a positive correlation between humor as a character strength and the socially warm (vs. cold) humorous style; i.e., the first and major factor underlying everyday humorous conduct. The socially warm vs. cold factor describes the tendency to use humor to promote good will vs. an avoidance or aloofness regarding mirthful behavior. Sample statements for the socially warm style are items like "maintains 
group morale through humor" or "uses good natured jests to put others at ease." Elements of the definition by Peterson and Seligman (2004), such as, "sustaining good cheer in the face of despair", "building social bonds", and "lubricating social interaction" refer to the socially warm humor style and there also is item content overlap between HBQD and the VIA-humor scale. It is expected that while the correlation will be high it will not be perfect due to different reasons. For example, the HBQD factor is bipolar, also involving the socially cold elements, but humor as a strength is unipolar--like all strengths in the VIA-classification. Furthermore in the HBQD the answer format is ipsative (not allowing people to be high in all scales but high scores in one are compensated by low scores in the other scales).

\section{Humor and virtues}

Peterson and Seligman (2004) assigned humor to the virtue of transcendence but acknowledged there were others options too. "In some cases, the classification of a given strength under a core virtue can be debated. Humor, for example, might be considered a strength of humanity because playfulness can create social bonds. It might also be classified as a wisdom strength, inasmuch as humor helps us acquire, perfect, and use knowledge. But we consider humor a strength of transcendence: Like hope and spirituality, humor connects us to something larger in the universe, specifically the irony of the human condition, the incongruent congruencies to which playful people call our attention, for our education and amusement “ (p.31). In a recent study humor (i.e., the items of 12 current instruments) was compatible with all virtues but most strongly with the humanity, wisdom and transcendence (Beermann \& Ruch, 2009). 
One may argue that virtues affect the expression (or non expression) and appreciation of humor in a variety of ways. In the past under the influence of humanism, in as much as people started to distinguish between the benevolent, philanthropic, laughing with forms of humor and laughing at people. This eventually shaped the concept of sense of humor, which since then typically was associated with love and the "good heart" (Schmidt-Hidding, 1963). Hence we expect positive correlations between humor as a strength, sense of humor and the socially warm humor style and the strengths assigned to the virtue of humanity (i.e., love, kindness, and social intelligence). Furthermore, we expect a positive correlation between the strength of wisdom and knowledge and the benign vs. mean-spirited factor, which describes persons having pleasure in mentally stimulating and innocuous humorrelated activities (e.g., "Enjoys witticisms which are intellectually challenging”) vs. having the tendency to use humor to attack or belittle others. The low pole of this dimension seems to express vice, or at least the absence of virtue. It is expected that mean spirited humor will be correlated with the absence temperance, humanity and justice. Thus, here different hypotheses are put forward for the two styles loaded on the opposing poles of the dimension. This is in line with the finding of Ruch et al. (2011) who found that the bipolarity of the styles is not given for all pairs of styles. Thus, it will be necessary to analyze not only the five bipolar humor factors, but also the 10 unipolar styles. Furthermore, a temperance might also be negatively correlated with the earthy vs. repressed factor which describes a harsh delight in joking about taboo topics on the positive pole and an inhibition concerning macabre, sexual or scatological modes of humor on the negative.

The two remaining HBQD dimensions do not show an apparent link to virtues and no hypotheses were put forward. The reflective vs. boorish factor describes 
people who discern the spontaneous humor found in doings of oneself, other persons or everyday occurrences (e.g., "Jokes about problems to make them seem ridiculous”) vs. the use of an uninsightful, insensitive and competitive use of humor. The competent vs. inept factor describes active wit, the capacity to convey humorous anecdotes effectively (e.g., "Manifests humor in the form of clever retorts to other's remarks") vs. the lack of skill and confidence in dealing with humor.

\section{Aim of the study}

The aim of the study was twofold. (1) To examine the relation between humor as a strength and the sense of humor (SHS), and to locate the former within a factorially comprehensive taxonomy of humor (HBQD). The expectation was to find high convergence between humor as a strength, the sense of humor and the socially warm humorous style of the HBQD. (2) To investigate the relationship between humor (as a strength, sense of humor and the humorous styles measured by the HBQD) and the character strengths and the related virtues measured by the VIA-IS.

\section{Method}

\section{Participants}

The sample consisted of $N=203$ participants; 84 were males and 119 were females. The mean age of the participants was $39.12(S D=15.49)$ and ranged from 18 to 76 years. The sample was highly educated; $51.6 \%$ held a degree from a university or a college of higher education.

\section{Material}

The Values in Action Inventory of Strengths (VIA-IS; Peterson et al., 2005), adapted to German by Ruch et al. (2010) consists of 240 items in a 5-point Likert-style format 
(from 1 = "very much like me" to 5 = "very much unlike me"). The self-assessment of the 24 character strengths (10 items per strength) included the classification by Peterson and Seligman (2004). A sample item is "Whenever my friends are in a gloomy mood I try to tease them out of it" (humor). The scale is widely used in research and all scales show acceptable reliabilities. Alpha coefficients in this sample ranged from .61 (authenticity) to .89 (creativity, religiousness; median $=.76$ ) and were comparable to former studies (Peterson \& Seligman, 2004).

The Sense of Humor Scale (SHS; McGhee, 1999; German adaptation by Proyer, Ruch \& Müller, 2010) consists of 40 items in a 7-point answer format ( 1 = "strongly disagree" to $7=$ "strongly agree") measuring playful vs. serious attitude (8 items; sample item: "I am in a serious frame of mind most of the time."), positive vs. negative mood (8 items; "I have a lot of joy in my life."), and sense of humor (24 items; "It is important for me to have a lot of humor in my life"). The latter is composed of six facets (with 4 items each), namely enjoyment of humor, verbal humor, humor in everyday life, laughing at yourself, and humor under stress. The alpha coefficients in the present study were .66 for playful/serious attitude, .85 for positive/negative mood and .87 for sense of humor, and .90 for the total score.

The Humorous Behaviour Q-Sort-Deck (HBQD; Craik et al., 1996) consists of 100 statements describing humor-related behaviors or behavior tendencies, in a 9 point answer format ( $1=$ "very uncharacteristic" to $9=$ "very characteristic") with the following distribution: $5,8,12,16,18,16,12,8,5$. The statements were aggregated to five bipolar styles of humorous conduct, namely socially warm vs. cold, reflective vs. boorish, competent vs. inept, earthy vs. repressed, and benign vs. mean-spirited humorous style. A sample item is: "Maintains group morale through humor" (socially warm). The five factors were recovered from a principal component analysis of the 10 
styles (Eigenvalues 1-7: 4.29, 2.74, 2.22, 1.34, 1.05, 0.90, and 0.81), each represented by two item parcels consisting of 3 to 8 items each. Five factors explaining 59.54\% of the variance were rotated to the OBLIMIN criterion $($ Delta $=0)$. The intercorrelations of the factors ranged from $r=.00$ (earthy versus repressed with reflective versus boorish) to $r=-.20$ (earthy versus repressed with competent versus inept) with a median of .05. Results showed that the bipolarity of the 10 styles was evident with the exception of mean-spirited humor, which not only seemed to be opposite to benign style but also the repressed style. In other words, two item parcels representing mean spirited humor not only loaded negatively on the benign vs. mean-spirited factor, but also (and more highly so) positively on the earthy versus repressed factor.

\section{Procedure}

The adaptation of the HBQD. The first German translation (e.g., Ruch et al., 2011) was revised as some of the items yielded unexpected results and also the five-factor structure could not be well replicated. This revision involved several steps including a new translation of all items, followed by an independent back translation. A native speaker compared the translation to the original English items and discrepancies were highlighted. In case the original meaning of the items was not well represented, the authors of the HBQD were asked to comment on the revision.

\section{Data collection}

Participants filled in paper and pencil version of the two humor questionnaires (SHS and HBQD) and the VIA-IS online. They did not receive any payment but were provided feedback about their scores relative to other respondents. 


\section{Results}

Relations between the humor scales

Correlations between demographics and all scales that entered the study yielded coefficients compatible with prior findings. Although they were generally low $\left(r^{2}<.10\right)$ the subsequent analyses controlled for age and gender. For an examination of the substance overlap of the three humor questionnaires used in this study, partial correlations among the five the SHS facets, HBQD factors, and the VIA-humor scale, were computed. Table 1 shows the respective correlation coefficients of the SHS scales, VIA-IS humor and the HBQD humor factors.

Insert Table 1 about here

Table 1 shows that the three humor concepts overlapped very well. The pair wise correlation between the VIA-IS humor scale, sense of humor and socially warm vs. cold humor yielded coefficients between $r=.58$ and $r=.63$. However, both VIAIS humor and sense of humor also showed relations to other HBQD styles, most notably with competent ( $r=.27$; VIA-IS humor; $r=.29$; sense of humor) and earthy humor ( $r=.28$; SHS only). Two multiple regressions analyses were performed with the five HBQD styles as predictors and humor as a strength and sense of humor as criteria; the inspection of the beta weights will allow to see whether competent humor (or any of the other styles) has incremental validity on top of socially warm vs. cold humor. The analysis showed that the HBQD styles explained both of the humor concepts very well ( $R=.64$ and .67 , respectively). However, the beta coefficients were only high for socially warm vs. cold humor $(.55, .56$, both $p<.001)$ while the beta coefficients for competent vs. inept were low for both VIA-IS humor and sense of humor ( $\beta=.16$, and .10 , respectively) and only reached significance for VIA-IS 
humor $(p<.05)$ while for sense of humor, the coefficient just failed to reach significance $(p<.059)^{1}$. Earthy vs. repressed was significant when predicting sense of humor $(\beta=.23, p<.001)$ and to a smaller amount when predicting humor as strengths $(\beta=.14, p=.05)$. Furthermore, also reflective vs. boorish humor was a significant predictor for sense of humor $(\beta=.11, p<.05)$.

A closer look at the SHS facets showed that all of the facets yielded relations to the HBQD styles. The earthy humorous style was related to the facets verbal humor and laughing at yourself. Boorish humorous style indicated enjoyment of humor. The results is compatible with the assumption that the humor skills are ordered according to their difficulty (McGhee, 1999). The facets more difficult to develop showed positive correlations with reflective and competent humor (i.e., finding humor in everyday life: $r=.20 ; .25$; laughing at yourself: $r=.20 ; .29$; humor under stress: $r=.19 ; .30)$. The facets assumed to be easily developed did not or negatively correlate with both humor styles. Multiple regression predicting each of the facets by entering the five HBQD styles yielded coefficients between $R=.42$ (enjoyment of humor) and $R=.61$ (verbal humor).

Playfulness plays an important role in the VIA-classification (as it is understood synonymous with humor) and it builds the basis of sense of humor in the SHS. As expected humor in the VIA-IS and the playful/serious attitude share a high amount variance $(r=.55)$. However, it is important to examine whether playfulness has incremental validity (in addition to sense of humor) in predicting humor as strengths. A stepwise regression predicting humor as strength by entering the three SHS scales yielded an $R$ of .66 and showed that the sense of humor was most predictive $(\beta=.54, p<.001)$ and that playful attitude played an additional but minor role $(\beta=.18, p<.01)$. Positive vs. negative mood did not contribute to humor as 
strength $(\beta=.04)$. Similarly, sense of humor was most predictive of the socially warm style $(R=.60, \beta=.42, p<.001)$ and positive mood was not predictive $(\beta=-.01, \mathrm{~ns})$. However, a playful attitude played a bigger role $(\beta=.29, p<.001)$ and raised the multiple correlation to $R=.64$.

\section{Humor and character strengths}

Partial correlations, controlled for age and gender, were computed between the character strengths, the sense of humor and the humor styles. In order to systematize these results the coefficients were averaged across the strengths of each virtue using only the purest markers ${ }^{2}$ (for results see Table 2).

Insert Table 2 about here

Table 2 shows that the correlation coefficients between the 23 character strengths and the VIA-IS humor ranged from $r=-.04$ to $r=.54$ (kindness) with a median of .27 , for sense of humor from $r=-.19$ (modesty) to $r=.34$ (love; $M d n=.16$ ) and for socially warm vs. cold from $r=-.23$ (modesty) to $r=.37$ (love) with a median of .17. These three different humor conceptualizations also showed similar correlational patterns with highest relations to creativity, bravery, zest, love, kindness and social intelligence. The VIA-IS humor yielded the numerically highest correlation coefficients (perhaps due to stronger method overlap); the HBQD yielded the lowest (presumably due to the different answer format). Table 2 also shows that these three humor conceptualizations primarily related to humanity, with a weaker relation to courage (primarily based on bravery and zest). The strengths of wisdom and knowledge were not related to these three but creativity and curiosity were.

Playfulness, as a motor of the sense of humor and the strength akin to the VIA-IS humor had indeed a similar profile of correlations as the three prime humor 
scales. The correlations between the 23 character strengths and playful/serious attitude ranged from $r=-.23$ (prudence) to $r=.42($ love; $M d n=.13)$. While this attitude correlated substantially with single strength it was only consistently related to strengths of humanity. As a bipolar scale some of the coefficients (i.e., to temperance) might be due to the seriousness side of the dimension. The scale of positive/negative mood showed a few high correlations (ranging from $r=-.04$ to $r=.52$, hope; $M d n=.19)$ but showed only consistent relations to courage and justice.

The correlations for the remaining $\mathrm{HBQD}^{3}$ factors were lower than for socially warm vs. cold and there were clearly different patterns. For reflective vs. boorish the coefficients ranged from $r=-.19$ (zest, kindness) to $r=.13$ (open-mindedness; $M d n=-.04)$ and none of the virtues were systematically involved. The coefficients for competent vs. inept ranged from $r=-.29$ (modesty) to $r=.26$ (bravery; $M d n=.02)$ and they did not cumulate around a specific virtue. The coefficients for earthy vs. repressed ranged from $r=-.37$ (prudence) to $r=.15$ (bravery; $M d n=-.16$ ) and repressed humor seemed to be systematically associated with temperance, and to a lower extent, with justice and transcendence. Finally, for benign vs. mean-spirited the coefficients ranged from $r=-.09$ to $r=.22$ (love of learning; $M d n=.12$ ) and while Table 2 shows mean correlation coefficients that were different from zero one can see that for none of the virtues each of the selected strengths were involved.

As not all factors were perfectly bipolar, partial correlations were also computed between the VIA-IS strength and the first unrotated factor extracted from the items defining each of the 10 styles. Indeed, looking at the poles separately a very different pattern emerged. As expected, mean-spirited humor was highly negatively correlated with each of the selected strengths of justice $(M=-.31)$ and temperance $(M=-.30)$, but also of transcendence $(M=-.27)$. Furthermore, individual, but not all 
strength of humanity $(M=-.20)$, courage $(M=-.19)$ and wisdom $(M=-.14)$ reached significance. Benign humor did not show the opposite correlation pattern. On the contrary, none of the virtues was systematically related to benign humor. The expected relationship with the strengths of wisdom $(M=.15)$ could not be substantiated; while two of the strengths showed the expected positive correlations (curiosity: $r=.20$; love of learning: $r=.24$ ), the other three were not systematically related. The imperfect bipolarity of these two styles was underscored by the fact that first unrotated factors from the benign items and the mean-spirited items only correlated slightly negative $(r=-.26 ; p<.01)$.

Furthermore, while the socially warm vs. socially cold factors clearly were opposite $(r=-.63, p<.001)$, the socially warm and cold scales did not show a clear bipolar pattern. Socially warm humor was not only highly correlated with humanity $(M=.36)$, but also to a smaller amount with the strengths of transcendence $(M=.19)$, except beauty, which did not show significant correlation. In contrast, socially cold humor was also highly correlated with humanity $(M=-.25)$ and additionally with individual but not all of the selected strengths of temperance $(M=.26$; modesty: $r=.35$; prudence: $r=.34$ ). Finally, the earthy scale was highly negatively correlated with all of the selected strengths of temperance $(M=-.23)$, while the repressed scale did not show significant correlations to any of the strengths. The factors extracted from the earthy vs. repressed humor style items were highly negatively correlated $(r=-.57, p<.001)$. The correlation for reflective vs. boorish $(r=-.41, p<.001)$ and competent vs. inept $(r=-.34, p<.001)$ item sets were in the mid range but like for earthy vs. repressed they produced opposite correlational patterns. 


\section{Discussion}

The first aim of the study was to investigate humor as strength within the framework of two other conceptualizations of humor, namely the sense of humor (McGhee, 1999) and the five styles of everyday humorous conduct (Craik et al., 1996). The results confirmed the assumptions that these three concepts do overlap to a high extent, albeit not perfectly. The imperfect overlap lies in both methodological and content-related issues. Regarding the former it is clear that imperfect reliability lowered the correlations and correction for attenuation boosts the coefficients by app. 10 and the resulting coefficients are between .69 and.73. Furthermore, the sense of humor scale and the VIA-IS scale are unipolar and only contain positively keyed items while the socially warm and cold scale is bipolar and the balanced keying allows for a better control of acquiescence. Finally, the scales differ regarding the answer formats (e.g., ipsative vs. rating format); the Q-sort method limits the variation in scores in socially warm vs. cold scale as these are perfectly predicted by a linear combination of the other four styles. Regarding the contents, all three emphasize laughter and positive emotions, and maintaining good cheer during adversity. However, the concepts also have unique elements; only the sense of humor concept involves the element of enjoyment of humor and only the socially warm vs. cold style elaborated the lower end of the continuum. Therefore, as expected, the facets of enjoyment of humor was the one SHS facet with the lowest correlation with the VIA-IS humor scale (and the socially warm vs. cold humor style). The items of the socially cold style reflect contents like being only humorous in the company of close friends or that can only laugh with difficulties at personal failings. Not surprisingly, this dimension of socially warm vs. socially cold humor shows a negative relation to modesty, while the VIA-IS humor scale does not. Finally, the VIA-IS scale merges playfulness (albeit with only 
few items) and humor in one concept whereas playfulness and sense of humor are kept separate in the SHS and the socially warm vs. cold styles does not mention play at all. Future studies might want to apply all items of the three humor scales in the same answer format to a sample of participants to test whether or not a single factor accounts for the variation in this joint item pool.

Like socially warm humor, also sense of humor and humor as strength correlated with competent humor. This replicates findings of Craik et al. (1996) that showed that a sense of humor-index correlated most highly $(r=.59)$ with socially warm vs. cold humor and also positively with competent humor $(r=.32)$. This suggests that the socially constructive uses of humor and the (self-reported) active wit and ability to tell jokes effectively are positively correlated. When controlling for the intercorrelation between the socially warm vs. cold and the competent vs. inept humor (.30 in Craik et al., 1996) both the sense of humor measure and humor as strengths still correlate positively to the extent of .19 with the competent humor style (partial correlation). This is exactly the same coefficient that can be computed for the results given by Craik et al. (1996). However, linear regression showed, that competent humor was not the only predictor besides socially warm humor. For humor as strength, also earthy humor was a significant predictor. Interestingly earthy and reflective humor did both prove to be better predictors for sense of humor than competent humor. This implies that competent humor operates as a suppressor for other humor styles. Therefore, the sense of humor goes beyond the social benevolent use of humor and includes a perceived competence and pensive humor, which is noninhibited. It appears that the inclusion of self-reported ability is a key distinguishing factor that separated socially warm vs. cold humor and both humor as a strength and the sense of humor by making the former appear more narrow compared to the latter 
two. Consequently, this raises the question, which cannot be answered yet, whether this perceived ability is an essential part of sense of humor and humor as a strength or this is only an artifact due to mixture of use of temperament and ability words in the item pool. Studies on the nature of the sense of humor are needed that explore the typical and maximal behavior elements; how much is temperament and how much of humor is ability. It should be noted that self-reports of wit are typically not substantially related to performance measures of humor creation (Ruch, 2004).

The present study demonstrates that playfulness, as the motor of sense of humor, shows the same pattern of relationship as sense of humor and socially warm humor. This validates the conceptualization of humor in the VIA-classification, where humor and playfulness are merged into one concept. The dimension positive vs. negative mood shows the same pattern of relationship, but to a lower amount. Hence, McGhee's (1999) model of sense of humor and its underlying dimensions are supported by this data.

The remaining two HBQD humor styles (reflective vs. boorish and benign vs. mean-spirited) were not related to the VIA-IS humor scale. This is a consequence of restricting humor as character strengths to “... those forms of humor that serve some moral good" (Peterson \& Seligman, 2004; p. 530). While humor styles with a negative connotation were excluded it is still surprising that mean-spirited humor is not negatively related to humor as character strength.

The second aim of the study was to further illuminate the relationship between humor and virtues. The findings clearly support the prime assignment of humor to humanity. This could not only be found for humor as strengths, but also for the sense of humor and socially warm humor. This is compatible of the findings that experts rated the VIA-IS humor items to be most prototypical for humanity and, to a lower 
extend, to transcendence (Beermann \& Ruch, 2009). Humor seems to be a good vehicle to express humanity, i.e., to relate to others in a kind, empathetic, and benevolent way. Indeed, a couple of centuries ago the rise of humanism shaped the meaning of humor by bringing forward the distinctions of "good humor" vs. "bad humor" and "true wit" vs. "false wit"; i.e., the separation of laughing with and laughing at (Ruch, 2004). Apparently, the impact of humanism was strong and lasting and did not only form the meaning of the sense of humor but even today the major factor underlying the $100 \mathrm{HBQD}$ items represents humanity.

Interestingly, humor as a strength was highly related to all but one (i.e., temperance) of the six virtues. This might be a bit inflated by sharing the same answer format, but at least courage is also related to sense of humor and socially warm humor. However, there is also evidence that the VIA-IS humor scale does not cover all the humor styles that are potentially virtuous. The strongest relation to (the absence of) virtuous behavior showed mean-spirited humor, with negative correlations to five out of six virtues (exception: wisdom and knowledge). Mean-spirited humor was antagonistic to strengths of justice, temperance, and transcendence. Likewise, also earthy humor was negatively related to the absence of virtue; it was negatively related to temperance (but also transcendence and justice). Interestingly, no such correlations were found for repressed humor; i.e., the opposite humor style for which the hypotheses was set up. Furthermore, the strengths of temperance also related to socially cold humor. Thus, temperance is antagonistic to expressing the harsh delight in joking about taboo topics (i.e., earthy humor) and converges with an avoidance or aloofness regarding mirthful behavior (i.e., socially cold). In sum, like in the prior study (Beermann \& Ruch, 2009) all six virtue categories were compatible with humor and three of the humor styles correlated with the virtue indicators. Both competent vs. 
inept and reflective vs. boorish failed to correlate clearly with any virtue. Reflective (i.e., discerning the spontaneous humor found in doings of oneself, other persons or everyday occurrences) and competent (i.e., active wit, the capacity to convey humorous anecdotes effectively) at least have a weak overlap with the strengths of wisdom and knowledge. A potential relationship has been weakened, at least in part, by the differences in answer format and a study using the five styles in a rating format is required. However, both competent and reflective tended to correlate with the component of the sense of humor that are more difficult to acquire (McGhee, 1999). Clearly, more research is needed but so far it is safe to state that at least three out of the five styles relate to virtues. It needs to be added though that in the present study no direct measure of virtue was utilized but prototypical character strengths were aggregated to form an index for the six virtues.

Recently, McGhee (2010) stated that even though humor contributes to positive psychological functioning there seems to be lack of interest in humor within Positive Psychology, This might be, in part, due to the fact that the morally good is not so salient, or perhaps because wit also may be guided by vice. The present study not only clearly showed the strong link between benevolent forms of humor and humanity, but also the various ways in which virtues are involved in not showing mean-spirited and earthy forms of humor behaviors.

The present study is limited to the five dimensions inherent in the HBQD. In the present study the same factors were found than the ones reported by Craik et al. (1996) when analyzing item parcels. However, a closer look at the 10 unipolar humor styles showed that the bipolar structure of the five factors is not given for all of the styles. Especially the benign and the mean-spirited humor styles seem to be only weakly antagonistic. A further problem with this factor already emerged in the study 
by Ruch et al. (2011). They found that the self-evaluation of earthy vs. repressed correlated more highly with the peer evaluation of benign vs. mean-spirited humor style that the self-evaluation of benign vs. mean-spirited did. Thus, earthy humor was considered as mean-spirited by peers. Future studies of humor and virtues should also incorporate peer assessments, and ideally a direct assessment of virtues. 


\section{References}

Beermann, U. \& Ruch, W. (2009). How virtuous is humor? What we can learn from current instruments. The Journal of Positive Psychology, 4, 528-539. doi:10.1080/17439760903262859

Craik, K. H., Lampert, M. D., \& Nelson, A.J. (1996). Sense of humor and styles of everyday humorous conduct. Humor: International Journal of Humor Research, 9, 273-302. doi:10.1515/humr.1996.9.3-4.273

McGhee, P. E. (1999). Health, healing and the amuse system: Humor as survival training (3rd ed.). Dubuque: Kendall/Hunt Publishing Company.

McGhee, P. E. (2010). Humor: The lighter path to resilience and health. Bloomington: AuthorHouse.

Park, N., Peterson, C., \& Seligman, M. E. P. (2004). Strengths of character and wellbeing. Journal of Social and Clinical Psychology, 23, 603-619. doi:10.1521/jscp.23.5.603.50748

Park, N., Peterson, C., \& Seligman, M. E. P. (2006). Character strengths in fifty-four nations and the fifty US states. Journal of Positive Psychology, 1, 118-129. doi:10.1080/17439760600619567

Peterson, C., Park, N., \& Seligman, M. E. P. (2005). Assessment of character strengths. In P. Koocher, J. C. Norcross, \& S.S. Hill III (Eds.), Psychologists' desk reference ( $2^{\text {nd }}$ ed., pp. 93-98). New York: Oxford University Press.

Peterson, C., Park, N., \& Seligman, M. E. P. (2006). Greater strengths of character and recovery from illness. Journal of Positive Psychology, 1, 7-26. doi:10.1080/17439760500372739 
Peterson, C., Ruch, W., Beermann, U., Park, N., \& Seligman, M. E. P. (2007).

Strengths of character, orientation to happiness, and life satisfaction. The Journal of Positive Psychology, 2, 149-156. doi:10.1080/17439760701228938

Peterson, C., \& Seligman, M. E. P. (2004). Character strengths and virtues: A handbook and classification. New York: Oxford University Press.

Proyer, R. T., Ruch, W., \& Müller, L. (2010). Sense of humor among the elderly: Findings using the German version of the SHS. Zeitschrift für Gerontologie und Geriatrie, 43, 19-24. doi:10.1007/s00391-009-0082-0

Ruch, W. (2004). Humor (playfulness). In C. P. Peterson \& M. E. P. Seligman (Eds.), Character strengths and virtues: A handbook and classification (pp. 583-598). New York: Oxford University Press.

Ruch, W. (2008). The psychology of humor. In V. Raskin (Ed.), A primer of humor research (pp. 17-100). Berlin: Mouton de Gruyter.

Ruch, W., Proyer, R. P., Esser, C., \& Mitrache, O. (2011). Cheerfulness and everyday humorous conduct. In Romanian Academy, “George Barit“" Institute of History, Department of Social Research (Ed.), Studies and researches in social sciences (Vol. 18). Cluj-Napoca, Romania: Argonaut Press.

Ruch, W., Proyer, R. T., Harzer, C., Park, N., Peterson, C., \& Seligman, M. E. P. (2010). Adaptation and validation of the German version of the Values in Action Inventory of Strengths (VIA-IS) and the development of a peer-rating form. Journal of Individual Differences, 31, 138-149. doi:10.1027/1614-0001/a000022 Schmidt-Hidding, W. (1963). Europäische Schlüsselwörter. Band I: Humor und Witz [European key terms. Volume I: Humor and Wit] Munich, Germany: Huber. 


\section{Footnotes}

1. A closer look at the items showed that only a few SHS items were correlated with competent vs. inept humor after partialling out the effects of socially warm vs. cold humor (e.g., SHS10: My sense of humor rarely abandons me under stress $[r=.32]$; SHS35: I often make spontaneous witty remarks (no pun) $[r=.30]$; SHS25: I often create my own spontaneous puns $[r=.25])$. And vice versa of the competent items only one showed significant correlations to sense of humor (Item 84: Laughs without discriminating between more and less clever remarks" $[r=-.19]$ ) and one to humor as a strength (Item 68: Crushed when humorous efforts meet with less than enthusiastic reception $[r=-.17]$ )

2. In an expert rating $(n=44)$ study theologians, psychologists and philosophers but also laypersons $(n=35)$ rated how good examples each of the 24 strengths are for the six virtues. A few of the strengths had a considerable second relation to a further virtue and were not considered in this analysis. Thus, endurance (courage), social intelligence (humanity), teamwork (justice), leadership (justice), and forgiveness (temperance) were not used in the averaging.

3. As an aside it should be mentioned that the Q-Sort technique provides ipsative data. Pearson correlations between HBQD factors and ipsative ranked character strengths were computed as well. The same pattern arose as shown in Table 2. As expected, the same answering format led to higher correlation coefficients. 
Table 1. Partial correlations between the SHS scales, VIA-IS humor and the HBQD humor factors, controlling for age and gender.

\begin{tabular}{|c|c|c|c|c|c|c|c|}
\hline \multirow[b]{2}{*}{ Scales } & \multirow{2}{*}{$\begin{array}{l}\text { VIA-IS } \\
\\
\text { Humor }\end{array}$} & \multicolumn{6}{|c|}{ HBQD humor factors } \\
\hline & & $\begin{array}{c}\text { Socially } \\
\text { warm/ } \\
\text { cold }\end{array}$ & $\begin{array}{c}\text { Reflective/ } \\
\text { boorish }\end{array}$ & $\begin{array}{l}\text { Compe- } \\
\text { tent/inept }\end{array}$ & $\begin{array}{l}\text { Earthy/ } \\
\text { repressed }\end{array}$ & $\begin{array}{l}\text { Benign/ } \\
\text { mean- } \\
\text { spirited }\end{array}$ & $R$ \\
\hline \multicolumn{8}{|l|}{ SHS } \\
\hline Attitude & $.52 * * *$ & $.54 * * *$ & .05 & $.23 * *$ & .12 & $.15^{*}$ & .57 \\
\hline Mood & $.25 * * *$ & $.25 * * *$ & -.02 & .06 & -.10 & .13 & .29 \\
\hline $\mathrm{SOH}$ & $.63^{* * *}$ & $.58 * * *$ & .06 & $.29 * * *$ & $.28 * * *$ & $.15^{*}$ & .67 \\
\hline Enjoyment & $.29 * * *$ & $.33 * * *$ & $-.26 * * *$ & -.09 & .08 & .10 & .42 \\
\hline Laughter & $.50^{* * *}$ & $.50 * * *$ & -.08 & .13 & $.16^{*}$ & .07 & .57 \\
\hline Verbal & $.43 * * *$ & $.48 * * *$ & .02 & $.33 * * *$ & $.27 * * *$ & $.19^{* *}$ & .61 \\
\hline Everyday & $.52 * * *$ & $.43 * * *$ & $.20 * *$ & $.25 * * *$ & $.16^{*}$ & $.15^{*}$ & .54 \\
\hline $\begin{array}{l}\text { Laughing at } \\
\text { yourself }\end{array}$ & $.45^{* * *}$ & $.35 * * *$ & $.20 * *$ & $.29 * * *$ & $.28 * * *$ & .07 & .52 \\
\hline $\begin{array}{l}\text { Humor } \\
\text { under Stress }\end{array}$ & $.49 * * *$ & $.36 * * *$ & $.19 * *$ & $.30 * * *$ & $.22 * *$ & .07 & .50 \\
\hline HQ & $.63 * * *$ & $.59 * * *$ & .05 & $.27 * * *$ & $.19^{* *}$ & $.18^{*}$ & .66 \\
\hline $\begin{array}{l}\text { VIS-IS } \\
\text { humor }\end{array}$ & -- & $.59 * * *$ & -.04 & $.27 * * *$ & .13 & .10 & .64 \\
\hline
\end{tabular}

Note: $N=199$ - 203. Partial correlation controlled for age, gender. Attitude $=$ playful/serious attitude, Mood = positive/negative mood, $\mathrm{SOH}=$ sense of humor, Enjoyment $=$ enjoyment of humor, Verbal $=$ verbal humor, Everyday $=$ finding humor in everyday life, $\mathrm{HQ}=$ total score.

${ }^{*} p<.05 .{ }^{* *} p<.01 .{ }^{* * *} p<.001$. 
Table 2. Partial correlations between the scales of the VIA-IS (except humor), the five HBQD humor factors, SHS scales and the mean correlations across the six virtues controlled for age and gender.

\begin{tabular}{|c|c|c|c|c|c|c|c|c|c|}
\hline \multirow[b]{2}{*}{ VIA-IS } & \multirow{2}{*}{$\begin{array}{l}\text { VIA-IS } \\
\text { Humor }\end{array}$} & \multicolumn{3}{|c|}{ SHS } & \multicolumn{5}{|c|}{ HBQD humor factors } \\
\hline & & Attitude & Mood & $\begin{array}{l}\text { Sense of } \\
\text { humor }\end{array}$ & $\begin{array}{c}\text { Socially } \\
\text { warm/cold }\end{array}$ & $\begin{array}{l}\text { Reflective/ } \\
\text { boorish }\end{array}$ & $\begin{array}{l}\text { Competent/ } \\
\text { inept }\end{array}$ & $\begin{array}{l}\text { Earthy/ } \\
\text { repressed }\end{array}$ & $\begin{array}{c}\text { Benign/mean } \\
\text {-spirited }\end{array}$ \\
\hline Creativity & $.27 * *$ & .17 & .07 & $.27 * *$ & .17 & -.06 & .12 & .04 & .16 \\
\hline Curiosity & $.30 * *$ & $.30 * *$ & $.50 * *$ & $.25^{* *}$ & $.20 *$ & .04 & .12 & -.08 & $.19^{*}$ \\
\hline Open-mindedness & .01 & -.10 & -.02 & -.04 & -.18 & .13 & -.01 & -.17 & .08 \\
\hline Love of learning & $.22 *$ & .13 & $.21 *$ & .15 & .03 & .08 & .18 & -.09 & $.22 *$ \\
\hline Perspective & $.20^{*}$ & .09 & .08 & .16 & .06 & -.03 & .15 & -.05 & .08 \\
\hline Bravery & $.33 * *$ & $.21^{*}$ & $.21 *$ & $.26^{* *}$ & .18 & -.02 & $.26^{* *}$ & .15 & .09 \\
\hline Persistence & .15 & -.04 & $.30 * *$ & .00 & -.03 & -.18 & .14 & $-.19 *$ & .08 \\
\hline Honesty & $.26^{* *}$ & .10 & $.18^{*}$ & .08 & .11 & -.07 & .03 & -.18 & .12 \\
\hline Zest & $.41 * *$ & $.28 * *$ & $.46^{* *}$ & $.23 *$ & $.24^{*}$ & $-.19 *$ & .04 & -.16 & .08 \\
\hline Love & $.50 * *$ & $.42 * *$ & $.39^{* *}$ & $.34 * *$ & $.37 * *$ & -.01 & .08 & .00 & .16 \\
\hline Kindness & $.54 * *$ & $.27 * *$ & .14 & $.26^{* *}$ & $.32 * *$ & $-.19 *$ & -.01 & -.17 & .16 \\
\hline
\end{tabular}


Table 2 (continued). Partial correlations between the scales of the VIA-IS (except humor), the five HBQD humor factors, SHS scales and the mean correlations across the six virtues controlled for age and gender.

\begin{tabular}{|c|c|c|c|c|c|c|c|c|c|}
\hline \multirow[b]{2}{*}{ VIA-IS } & \multirow{2}{*}{$\begin{array}{l}\text { VIA-IS } \\
\text { Humor }\end{array}$} & \multicolumn{3}{|c|}{ SHS } & \multicolumn{5}{|c|}{ HBQD humor factors } \\
\hline & & Attitude & Mood & $\begin{array}{l}\text { Sense of } \\
\text { humor }\end{array}$ & $\begin{array}{c}\text { Socially } \\
\text { warm/cold }\end{array}$ & $\begin{array}{l}\text { Reflective/ } \\
\text { boorish }\end{array}$ & $\begin{array}{l}\text { Competent/ } \\
\text { inept }\end{array}$ & $\begin{array}{l}\text { Earthy/ } \\
\text { repressed }\end{array}$ & $\begin{array}{c}\text { Benign/mean } \\
\text {-spirited }\end{array}$ \\
\hline Social intelligence & $.37 * *$ & $.26^{* *}$ & .17 & $.24 * *$ & $.21^{*}$ & .06 & .07 & -.06 & .10 \\
\hline Teamwork & $.37 * *$ & $.18^{*}$ & $.20^{*}$ & .15 & $.21^{*}$ & -.04 & -.03 & $-.20 *$ & .05 \\
\hline Leadership & $.37^{* *}$ & .10 & $.21 *$ & .11 & $.21^{*}$ & -.10 & .00 & $-.27 * *$ & .06 \\
\hline Forgiveness & $.21^{*}$ & $.26^{* *}$ & $.33 * *$ & $.19^{*}$ & $.16^{*}$ & -.04 & -.02 & -.06 & .18 \\
\hline Modesty & -.03 & -.12 & .07 & $-.19^{*}$ & $-.23^{*}$ & .00 & $-.29 * *$ & $-.36^{* *}$ & -.09 \\
\hline Gratitude & $.34 * *$ & $.21 *$ & $.28 * *$ & .16 & $.20 *$ & -.12 & -.08 & $-.22 *$ & $.21 *$ \\
\hline
\end{tabular}


Table 2 (continued). Partial correlations between the scales of the VIA-IS (except humor), the five HBQD humor factors, SHS scales and the mean correlations across the six virtues controlled for age and gender.

\begin{tabular}{|c|c|c|c|c|c|c|c|c|c|}
\hline \multirow[b]{2}{*}{ VIA-IS } & \multirow{2}{*}{$\begin{array}{l}\text { VIA-IS } \\
\text { Humor }\end{array}$} & \multicolumn{3}{|c|}{ SHS } & \multicolumn{5}{|c|}{ HBQD humor factors } \\
\hline & & Attitude & Mood & $\begin{array}{c}\text { Sense of } \\
\text { humor }\end{array}$ & $\begin{array}{c}\text { Socially } \\
\text { warm/cold }\end{array}$ & $\begin{array}{c}\text { Reflective/ } \\
\text { boorish }\end{array}$ & $\begin{array}{c}\text { Competent/ } \\
\text { inept }\end{array}$ & $\begin{array}{c}\text { Earthy/ } \\
\text { repressed }\end{array}$ & $\begin{array}{c}\text { Benign/mea } \\
\text { n-spirited }\end{array}$ \\
\hline Hope & $.36^{* *}$ & $.29 * *$ & $.52 * *$ & .18 & $.19 *$ & -.14 & .04 & -.15 & .07 \\
\hline Religiousness & .11 & .09 & .17 & .05 & .14 & -.15 & -.17 & $-.24 * *$ & $.21 *$ \\
\hline \multicolumn{10}{|l|}{ Virtues } \\
\hline $\begin{array}{l}\text { Wisdom and } \\
\text { knowledge }\end{array}$ & .20 & .12 & .17 & .16 & .06 & .03 & .11 & -.07 & .15 \\
\hline Courage & .33 & .20 & .28 & .19 & .18 & -.09 & .11 & -.06 & .10 \\
\hline Humanity & .52 & .35 & .27 & .30 & .35 & -.10 & .04 & -.09 & .16 \\
\hline Justice & .27 & .08 & .19 & .03 & .08 & .00 & -.16 & -.15 & .18 \\
\hline Temperance & .00 & -.17 & .06 & -.14 & -.14 & -.08 & -.13 & -.34 & .00 \\
\hline Transcendence & .27 & .17 & .23 & .13 & .16 & -.09 & -.08 & -.19 & .17 \\
\hline$M$ & .27 & .13 & .20 & .11 & .11 & -.06 & -.02 & -.15 & .13 \\
\hline
\end{tabular}


Note: $N=$ 203. Partial correlation controlled for age, gender. Attitude $=$ playful $/$ serious attitude, Mood $=$ positive $/$ negative $\operatorname{mood}$, Beauty $=$ Appreciation of beauty and excellence.

${ }^{*} p<.01 .{ }^{* *} p<.001$. 